\title{
Corrigendum: Reprogramming to pluripotency is an ancient trait of vertebrate Oct4 and Pou2 proteins
}

Natalia Tapia, Peter Reinhardt, Annett Duemmler, Guangming Wu, Marcos J. Araúzo-Bravo, Daniel Esch, Boris Greber, Vlad Cojocaru, Cynthia Alexander Rascon, Akira Tazaki, Kevin Kump, Randal Voss, Elly M. Tanaka \& Hans R. Schöler

Nature Communications 3:1279 doi: 10.1038/ncomms2229 (2012); Published 11 Dec 2012; Updated 5 Feb 2013

In Fig. 1 and the first paragraph of the Discussion section in this Article, the genus Hydractinia is incorrectly referred to as hydra. The following sentence is correct: 'Interestingly, the recently identified Pou domain gene from Hydractinia ${ }^{18}$ appears to have the features of an Oct4/Pou 2 precursor gene, as shown in Fig. 1a, suggesting that the common Oct4/Pou 2 ancestor could have already existed even before the specification of vertebrates.'. The correct version of Fig. 1 appears below.

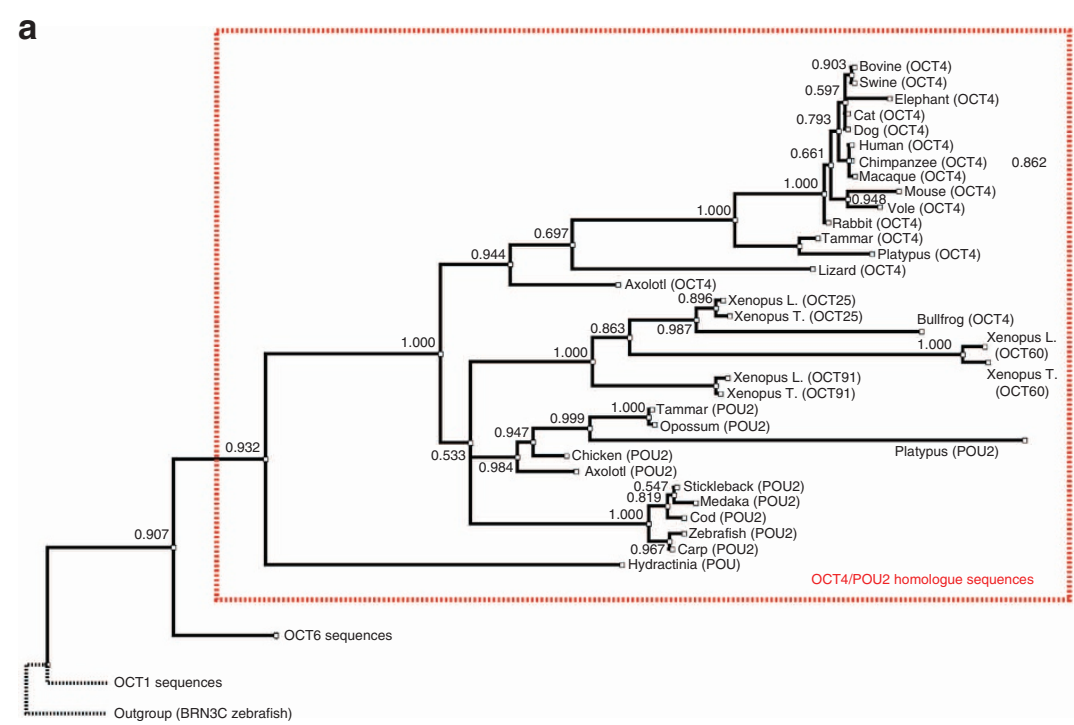

b
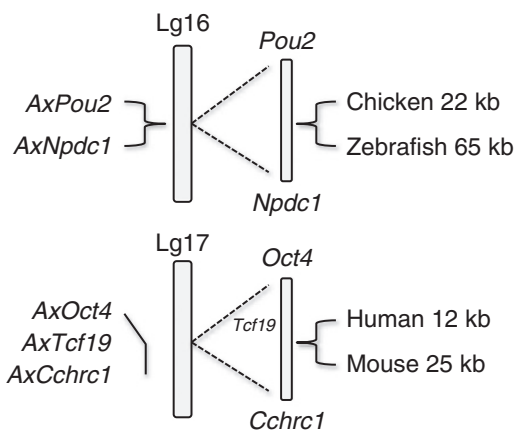